\title{
Prediction of parturition in Holstein dairy cattle using electronic data loggers
}

\author{
M. Titler, ${ }^{* 1}$ M. G. Maquivar, ${ }^{\star 2}$ S. Bas, ${ }^{*}$ P. J. Rajala-Schultz, ${ }^{*}$ E. Gordon, ${ }^{*}$ K. McCullough, ${ }^{*}$ P. Federico,† \\ and G. M. Schuenemann ${ }^{* 3}$ \\ ${ }^{*}$ Department of Veterinary Preventive Medicine, College of Veterinary Preventive Medicine, The Ohio State University, Columbus 43210 \\ †Department of Mathematics, Computer Science and Physics, Capital University, Columbus, $\mathrm{OH} 43210$
}

\section{ABSTRACT}

The objective of the present study was to assess the effect of parturition on behavioral activity [steps, standing time, lying time, lying bouts (LB), and duration of LB] $4 \mathrm{~d}$ before calving using electronic data loggers. Animals $(\mathrm{n}=132)$ from 3 herds were housed in similar freestall barns using a prepartum pen $21 \mathrm{~d}$ before the expected calving date and were moved into a contiguous individual maternity pen for parturition. Electronic data loggers were placed on a hind leg of prepartum heifers (heifers, $\mathrm{n}=33$ ) and cows (cows, $\mathrm{n}=99$ ) at $7 \pm 3 \mathrm{~d}$ before the expected calving date and removed at $14 \pm 3 \mathrm{~d}$ in milk. Calving ease (scale 1-4), parity, calving date and time, and stillbirth (born dead or died within $24 \mathrm{~h}$ ) were recorded. The number of steps (no./d), standing time $(\mathrm{min} / \mathrm{d})$, lying time (min/d), number of LB (no./d), and duration of LB $(\mathrm{min} / \mathrm{b})$ were recorded. Data were analyzed using MIXED procedures of SAS, adjusting for the herd effect. Only cows experiencing unassisted births (calving ease $=1$ ) were included in the study. An activity index was developed to predict calving time. Heifers and cows with unassisted births had significantly higher number of steps and longer standing time, decreased lying time, and more LB of shorter duration $24 \mathrm{~h}$ before calving compared with $\mathrm{d}-4,-3$, and -2 . Additionally, the number of LB increased as both heifers and cows approached labor starting on $\mathrm{d}-2$ and peaked at the day of calving. The time since the activity index increased over $50 \%$ to parturition did not differ between heifers and cows, and the activity index revealed the shift in activity on average $6 \mathrm{~h} 14 \mathrm{~min}$ (range from $2 \mathrm{~h}$ to $14 \mathrm{~h}$ $15 \mathrm{~min}$ ) before calf birth. This study provided evidence that heifers and cows approaching parturition showed a similar, but distinct, behavioral pattern that can be

\footnotetext{
Received December 10, 2014.

Accepted April 21, 2015.

${ }^{1}$ Current address: Big Valley Animal Hospital, Reedsville, PA

${ }^{2}$ Current address: Department of Animal Sciences, Washington State University, Pullman, WA 99163.

${ }^{3}$ Corresponding author: schuenemann.5@osu.edu
} 17084 . observed on average $6 \mathrm{~h}$ before calf birth. The potential benefits of electronic data loggers as predictors of parturition along with proactive management practices should improve the overall survival and welfare of both the dam and calf.

Key words: calving, prediction, precision management, dairy cattle

\section{INTRODUCTION}

For any dairy operation, calving is an essential requirement of the dairy production system in which cows initiate lactation and provide the future replacements of the herds. Parturition is divided into 3 stages (Noakes et al., 2001; USDA, 2010) that are characterized by hormonal, behavioral, and physical changes (e.g., dilation of soft tissues). Under normal conditions (eutocic births), parturition progresses gradually from one stage to the next (Wehrend et al., 2006; Miedema et al., 2011a,b; Schuenemann et al., 2011), ending with the delivery of the calf (Noakes et al., 2001; Schuenemann et al., 2011). Under field conditions, observations of the amniotic sac (AS) or feet of the calf outside the vulva are clear landmarks that calving personnel can easily identify to monitor calving progress (Schuenemann et al., 2011, 2013). In an ideal situation, calving personnel would monitor prepartum cows around the clock (24 h, $7 \mathrm{~d}$ per week) at regular intervals. In practice, however, the frequency of observation (calving personnel walking the pen and actually observing cows every $1 \mathrm{~h}$ ) is critical to determine the onset of the AS or feet of the calf outside the vulva and to identify cows in need of assistance (dystocia; Schuenemann et al., 2013) that likely results in stillbirth (Hunter et al., 2013). Therefore, development of monitoring systems that can predict calving time before the appearance of imminent signs of birth (AS or feet of the calf) would enable dairy producers and their personnel to implement a precision calving management program to help reduce undesirable calving-related events such as stillbirth due to late or no interventions.

The technology to monitor activity such as detecting cows in estrus using activity meters (Kamphuis et al., 
2012), pedometers (Chebel et al., 2013), or rumination devices (Reith and Hoy, 2012; Elischer et al., 2013) as well as health events (e.g., locomotion; Chapinal et al., 2011) are management tools available for dairy herds. The assessment of cow activity before parturition using electronic data loggers may provide an effective alert system for calving time as opposed to waiting for the imminent signs of labor (appearance of AS or feet of the calf). For instance, the frequency of transitions from lying to standing (Schuenemann et al., 2011) and restless behavior (e.g., pawing, walking) increased in the first stage of labor (Wehrend et al., 2006; Miedema et al., 2011a). This shift in calving-related activity may be identified by using a data-based activity index or algorithm and serve as a predictive tool that aids the typical visual observation by calving personnel. Therefore, the objective of the present study was to assess the effect of parturition on behavioral activity [steps, standing time, lying time, lying bouts (LB), and duration of LB] $4 \mathrm{~d}$ before and $1 \mathrm{~d}$ after calving using electronic data loggers (IceQube, IceRobotics, Edinburgh, UK). The hypothesis was that Holstein dairy cattle approaching parturition will exhibit a distinct behavioral activity that can be used to predict calving time.

\section{MATERIALS AND METHODS}

\section{Animals, Feeding, and Facilities}

In total, 132 pregnant Holstein animals (33 heifers and 99 cows) from 3 dairy herds were used in the present study. Briefly, cows were housed in freestall barns and milked thrice daily at approximately 8 -h intervals until dried off. Cows were fed twice daily, in the morning and afternoon, with a TMR formulated to meet or exceed dietary nutritional requirements for lactating and dry dairy heifers and cows (NRC, 2001). This study was conducted from July 2011 through August 2012. The procedures described below were reviewed and approved by The Ohio State University Institutional Animal Care Use Committee.

\section{Management of Animals and Calving}

Every week, a list of heifers and cows were obtained based on expected calving dates using on-farm computer records (Dairy Comp 305, Valley Agricultural Software, Tulare, CA). Pregnant cows (lactation $\geq 1$; cows) were dried off $60 \pm 3 \mathrm{~d}$ before the expected calving date and moved into the dry pen immediately after last milking. Similarly, pregnant heifers (lactation $=0$; heifers) were moved into the dry pens (separated from dry cows) $60 \mathrm{~d}$ before the expected calving date. Then, heifers and cows were moved into prepartum pens $21 \mathrm{~d}$ before the expected calving date. All heifers and cows were housed in similar prepartum pens and moved into a contiguous individual maternity pen for parturition. Pregnant animals were closely monitored by on-farm personnel for imminent signs of parturition (appearance of AS or feet of the calf outside the vulva) every $1 \mathrm{~h}$ (Schuenemann et al., 2011). All calving personnel received the same training at the beginning of the study (Schuenemann et al., 2013). The calving ease of cows (assistance provided at birth) were recorded using a 4 -point scale $(1=$ no assistance provided; $2=$ light assistance by one person without the use of mechanical traction; $3=$ mechanical extraction of the calf with an obstetric calf-puller; and $4=$ severe dystocia: surgery or fetotomy needed; Schuenemann et al., 2011). Only cows with calving ease of 1 were included in the present study. Body condition scores of all animals were assessed $7 \pm 3 \mathrm{~d}$ before calving using a 5 -point scale with 0.25-unit increments (Ferguson et al., 1994). Additionally, calving date and time, and stillbirth were recorded. Calving time $(0 \mathrm{~h})$ was recorded as the calf (single or twins) was expelled from the birth canal to the ground. Stillbirth was defined as a calf born dead or died (normal gestation length) within $24 \mathrm{~h}$ after birth (Schuenemann et al., 2011). After calving, cows were processed (e.g., harvesting of colostrum) and moved to the postpartum pens and calves were moved to a straw-bedded pen. All calves were fed colostrum (3.8 L) within $3 \mathrm{~h}$ after birth, their navel disinfected with a $7 \%$ iodine solution, and fitted with ear tags for identification. Subsequently, calves were moved to individual hutches until weaning.

\section{Calcium Status}

To assess the potential effect of hypocalcemia around the time of calving, blood samples $(8 \mathrm{~mL})$ for determination of serum calcium status were collected $7 \pm 3 \mathrm{~d}$ before the expected calving by coccygeal venipuncture (BD Vacutainer, Franklin Lakes, NJ). Briefly, blood samples were centrifuged at $2,785 \times g$ for 20 min at $4^{\circ} \mathrm{C}$ immediately after collection, and serum samples were stored at $-20^{\circ} \mathrm{C}$ until assayed for total calcium. Total serum concentration of calcium were determined in duplicates using a commercially available kit (Calcium Liquicolor No. 0150, Stanbio Laboratory, Boerne, TX) according to manufacturer's instructions. Cows were classified as hypocalcemic when the concentration of calcium from the blood sample was $\leq 8.0 \mathrm{mg} / \mathrm{dL}$ (Reinhardt et al., 2011). 


\section{Monitoring Cow Behavioral Activity}

Electronic data loggers (IceQube) were placed on a hind leg of prepartum heifers and dairy cows at $7 \pm 3 \mathrm{~d}$ before the expected calving date. Approximately at 14 \pm 3 DIM, data loggers were removed from the cows at milking time and data from individual lactating dairy cows were exported from IceManager software into an Excel spreadsheet (Microsoft Corp., Redmond, WA). Activity data in 15-min blocks from individual animals were summarized and reported hourly (h) and daily (d) for the number of steps (no.), standing time (min), lying time (min), number of LB (no.), and mean duration of LB (min).

\section{Activity Index to Predict Parturition}

An hourly activity index was developed to predict the time of calf birth. Briefly, a moving average over a 4 $\mathrm{h}$ period was computed for the number of steps (no./h), standing time $(\mathrm{min} / \mathrm{h})$, lying time $(\mathrm{min} / \mathrm{d})$, and $\mathrm{LB}$ (no./h) to smooth out short-term fluctuations and amplify longer-term trends. Then, the activity index for each animal was computed using the following formula:

$$
\text { activity index }=\frac{\text { number of steps } / \mathrm{h}}{\text { standing time } / \mathrm{h}} \times(\text { lying bouts } / \mathrm{h})^{2} \text {. }
$$

The changes in the overall mean number of steps (no./h) and LB (no./h) of Holstein dairy cows approaching parturition were considered when developing the activity index (Figure 1). Typically, prepartum animals (heifers or cows) transition more frequently from standing to lying positions as stage II (active labor) approaches. Therefore, the number of $(\mathrm{LB} / \mathrm{h})^{2}$ was used to increase the weight of this type of behavioral change in the overall activity as time of calving approached (Figure 1). Additionally, the developed activity index increased with the ratio between number of steps and standing time.

\section{Statistical Analyses}

Data from individual heifers and lactating dairy cows (e.g., parity, sex of calf, birth of twins, and stillbirth) were exported from DairyComp 305 into an Excel spreadsheet (Table 1).

Activity data such as number of steps, standing time, number of LB, and mean duration of LB during the $96 \mathrm{~h}$ before calving were summarized hourly (1-h period) and daily (24-h period) for the analysis. The daily activity patterns $4 \mathrm{~d}$ before parturition were analyzed using MIXED procedures of SAS (Table 2;
SAS Institute Inc., Cary, NC). A model that included parity (heifers or cows), calcium status, and BCS at calving was used to assess the effect of parturition on the activity parameters. Nonsignificant variables were eliminated from the model one at a time using the Wald statistic backward selection criterion $(P>0.15)$. Herd was included as a random effect. First order autoregressive, $\operatorname{AR}(1)$, covariance structure was used to account for the correlated data structure between the repeated daily measurements within animals. The differences in least squares means of the activity parameters (steps, standing time, LB, and mean duration of LB) among the $4 \mathrm{~d}$ before calving were computed by including the PDIFF option in the LSMEANS statement (Bas et al., 2011). The Tukey-Kramer method was used to obtain individual least squares means. Additionally, the herd $\times$ parity interaction was used to test the source of variation. Least squares means and standard errors of the means were reported. A $P<0.05$ was considered statistically significant.

An increase of at least $50 \%$ in the calculated activity index within the 4-d period before calving was considered the predictive time ( $\mathrm{h}$ and min) of calf birth. The time when this increase was observed in relation to the actual calving time $(0 \mathrm{~h})$ was recorded for each heifer and cow, and the predictive time interval calculated and summarized for both parity groups (Table $3)$. Furthermore, the predictive interval periods to calf birth were grouped into categories $(<4,4-7,>7 \mathrm{~h})$ to show the distribution (\%) of the time of activity change among Holstein dairy cattle (Table 3). Additionally, the activity index was plotted against time to graphically illustrate the time of behavioral changes $(\mathrm{h})$ before calf birth in one representative heifer and one representative cow approaching parturition, going through labor and calf birth $(0 \mathrm{~h})$, and initiating lactation (Figure 2).

\section{RESULTS}

A total of 132 prepartum animals (heifers and cows) experiencing unassisted births (calving ease score of 1 ) were included in the analyses (Table 1). Distribution of Holstein dairy heifers and cows with respect to lactation number, BCS $7 \pm 3$ d before calving, male calves, birth of twins, stillbirth, and hypocalcemia status are reported (Table 1 ).

\section{Effect of Parturition on Behavioral Activity Prior to Calving}

The herd $\times$ parity interaction did not differ. For both parity groups (heifers and cows), number of steps and standing time increased $(P<0.05)$, whereas daily 

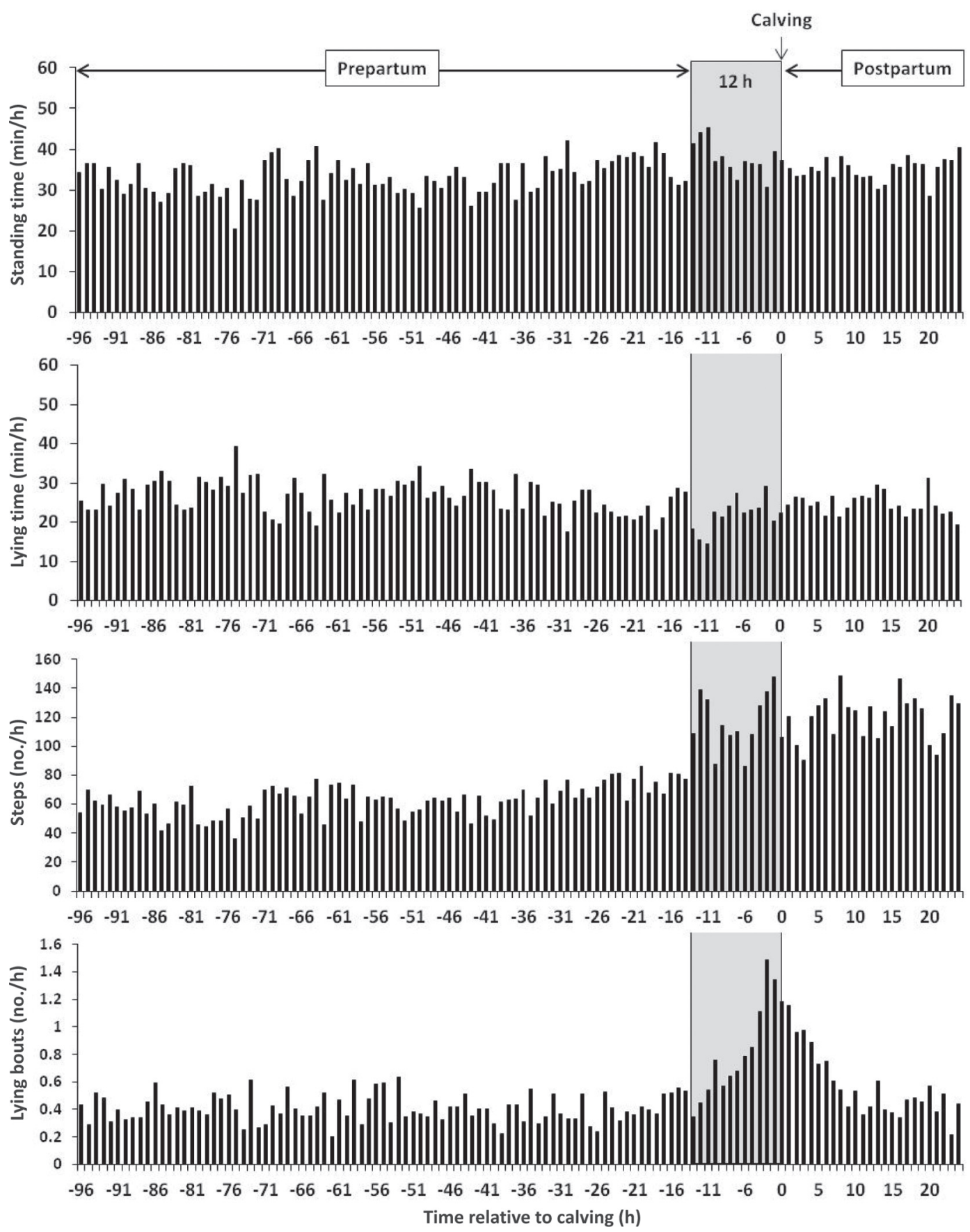

Figure 1. Overall mean standing time ( $\mathrm{min} / \mathrm{h})$, lying time $(\mathrm{min} / \mathrm{h})$, number of steps (no./h), and lying bouts (LB, no./h) $96 \mathrm{~h} \mathrm{before} \mathrm{and} 24$ $\mathrm{h}$ after calving in Holstein dairy cattle experiencing unassisted births. The overall mean distribution of activity patterns (steps, standing, lying, and LB) of Holstein cattle (heifers and cows combined; $\mathrm{n}=132$ ) were computed and reported hourly (solid black bars) $96 \mathrm{~h}$ before and $24 \mathrm{~h}$ after parturition. The solid black bars show the hourly behavioral activity as pregnant animals approach parturition (prepartum), go through labor and calf birth $(0 \mathrm{~h}$ ), and initiate lactation (postpartum). The gray rectangle shows the deviation in behavioral activity based on the number of steps and LB $12 \mathrm{~h}$ before calving $(0 \mathrm{~h})$.

lying time and duration of LB decreased $24 \mathrm{~h}$ before calving compared with $\mathrm{d}-4,-3$, and -2 (Table 2). In the present study, heifers spent less time standing and had fewer LB $24 \mathrm{~h}$ before calving compared with cows. Additionally, the number of LB increased as both heifers and cows approached labor starting on $\mathrm{d}-2$ and peaked at the day of calving $(-1 \mathrm{~d}$; Table 2 and Figure 1). Overall, heifers and cows experiencing unassisted 
Table 1. Distribution of unassisted births in Holstein dairy cattle with respect to lactation number, BCS, sex of calf, birth of twins, stillbirth, and hypocalcemia ${ }^{1}$

\begin{tabular}{|c|c|c|}
\hline Items & $\begin{array}{l}\text { Lactation }=1 \\
\quad(\mathrm{n}=33)\end{array}$ & $\begin{array}{l}\text { Lactation } \geq 2 \\
\quad(\mathrm{n}=99)\end{array}$ \\
\hline Lactation number (no.) & 1 & 3.05 \\
\hline $\mathrm{BCS}^{2}$ & 3.70 & 3.90 \\
\hline Male calves $(\%)$ & 48 & 53 \\
\hline Twins (\%) & 0 & 2.38 \\
\hline Stillbirth $^{3}(\%)$ & 3.03 & 2.02 \\
\hline Hypocalcemia $(\leq 8.0 \mathrm{mg} / \mathrm{dL})^{4}(\%)$ & 0 & 0 \\
\hline
\end{tabular}

${ }^{1}$ Unassisted births of Holstein dairy heifers (become lactation $=1$ after parturition) and cows (lactation $\geq 2$ ) were recorded at calving using a 4-point scale (Schuenemann et al., 2011) and only cows with calving ease score of 1 were included in the analysis.

${ }^{2}$ Body condition score was assessed $7 \pm 3 \mathrm{~d}$ before calving using a 5-point scoring system (Ferguson et al., 1994).

${ }^{3}$ Stillbirth was defined as a calf born dead or died within $24 \mathrm{~h}$ after births, and with a normal gestation length.

${ }^{4}$ The proportion (\%) of animals with hypocalcemia $(\leq 8.0 \mathrm{mg} / \mathrm{dL})$ was assessed $7 \pm 3 \mathrm{~d}$ before the expected calving using total serum calcium concentration (Reinhardt et al., 2011).

births had increased number of steps and LB (Table 2) with a pronounced activity change starting $12 \mathrm{~h}$ before calving (Figure 1). Furthermore, immediately after calving, the number of steps remained high, whereas LB gradually decreases (Figure 1) as cows transitioned from prepartum to the postpartum pen (i.e., adaptation to milking routine and new group of cows).

\section{Prediction of Parturition}

The predicted time from the moment of over $50 \%$ change in the activity index to parturition did not differ between heifers and cows (Table 3 ). Using the activity index, the overall predicted time before calf birth $(0$ h) was 6 h 14 min (range from 2 h to 14 h 15 min; Table 3). Additionally, the activity index was able to predict parturition with a time interval greater than 4 $\mathrm{h}$ in almost $76 \%$ of the prepartum animals (Table 3 ). An example is shown in Figure 2 as the activity index predicted calving time $9 \mathrm{~h} 15$ min before calf birth $(0$ h) for one heifer and 6 h 30 min before calf birth $(0 \mathrm{~h})$ for one cow.

\section{DISCUSSION}

The objective of this study was to assess the effect of parturition on daily behavioral activity patterns (steps, standing time, lying time, LB, and duration of LB) before calving. Through the use of electronic data loggers, the study showed that (1) behavioral activity changed within $24 \mathrm{~h}$ before parturition (increased number of steps and LB with decreased standing time and shorter duration of LB), (2) on average the activ-

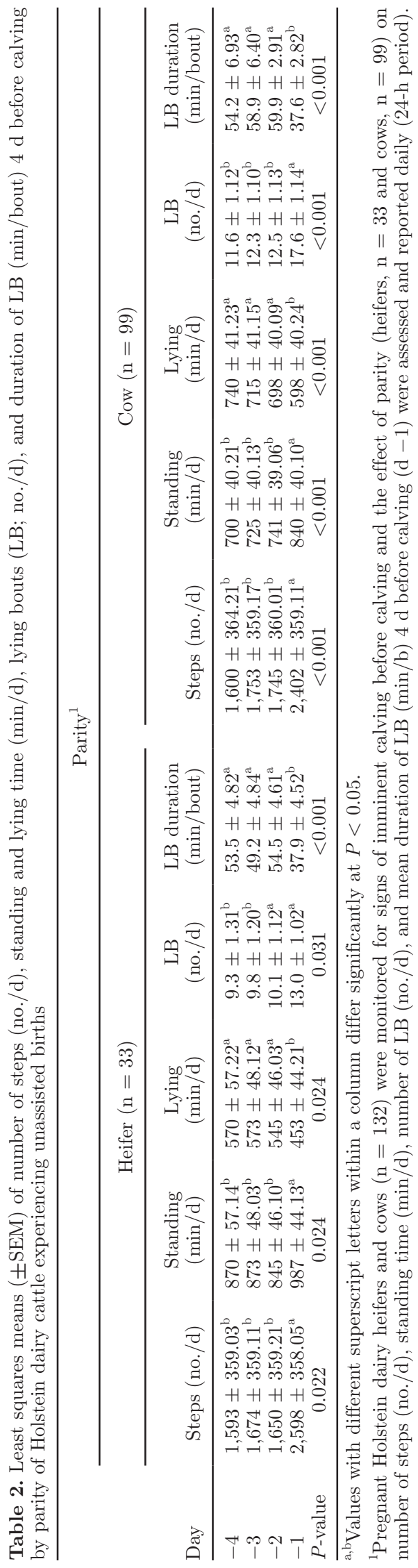


Table 3. Actual time (h) to parturition using the activity index in Holstein dairy cattle experiencing unassisted births

\begin{tabular}{|c|c|c|c|}
\hline \multirow[b]{2}{*}{ Items } & \multicolumn{3}{|c|}{ Time to predicted calving $^{1}$} \\
\hline & Mean & Median & Range \\
\hline Overall predicted time to calf birth & $6 \mathrm{~h} 14 \mathrm{~min}$ & $5 \mathrm{~h} 15 \mathrm{~min}$ & $2 \mathrm{~h}$ to $14 \mathrm{~h} 15 \mathrm{~min}$ \\
\hline Predicted time to calf birth in heifers & $6 \mathrm{~h} 18 \mathrm{~min}$ & $5 \mathrm{~h} 22 \mathrm{~min}$ & $2 \mathrm{~h}$ to $14 \mathrm{~h} 15 \mathrm{~min}$ \\
\hline \multirow[t]{3}{*}{ Predicted time to calf birth in cows } & $6 \mathrm{~h} 13 \mathrm{~min}$ & $5 \mathrm{~h} 22 \mathrm{~min}$ & $2 \mathrm{~h}$ to $14 \mathrm{~h} 15 \mathrm{~min}$ \\
\hline & \multicolumn{3}{|c|}{ Time interval $^{2}$} \\
\hline & $<4 \mathrm{~h}$ & 4 to $7 \mathrm{~h}$ & $>7 \mathrm{~h}$ \\
\hline Distribution of animals (\%) & 24.3 & 41.9 & 33.8 \\
\hline
\end{tabular}

${ }^{1}$ The time interval $(\mathrm{n}=132)$ was computed using the moment when a $50 \%$ increase in the activity index was observed and the actual time to calf birth was reported as mean, median, and range for all animals as well as for heifers and cows.

${ }^{2}$ The predicted times to calf birth were grouped into three time intervals $(<4,4-7$, and $>7 \mathrm{~h})$ according to distribution (\%) of Holstein dairy cattle (heifers and cows combined).

ity index was able to predict parturition $6 \mathrm{~h} 14 \mathrm{~min}$ before calf birth, and (3) the activity index predicted a similar time to calf birth (mean and range) for heifers and cows.

It is known that cows' behavior and activity patterns change as time to parturition approaches, regardless of difficulty at calving (Proudfoot et al., 2009; Schuenemann et al., 2011) or parity (Huzzey et al., 2005; Wehrend et al., 2006; Miedema et al., 2011a,b; Barrier et al., 2012; Jensen, 2012). The process of parturition is divided into 3 stages (Noakes et al., 2001; USDA, 2010) that are characterized by hormonal, behavioral, and physical changes (e.g., dilation of soft tissues). Under normal conditions (eutocic birth), parturition progresses gradually from one stage to the next (Wehrend et al., 2006; Miedema et al., 2011a; Schuenemann et al., 2011), ending with the delivery of the calf (Noakes et al., 2001; Schuenemann et al., 2011).

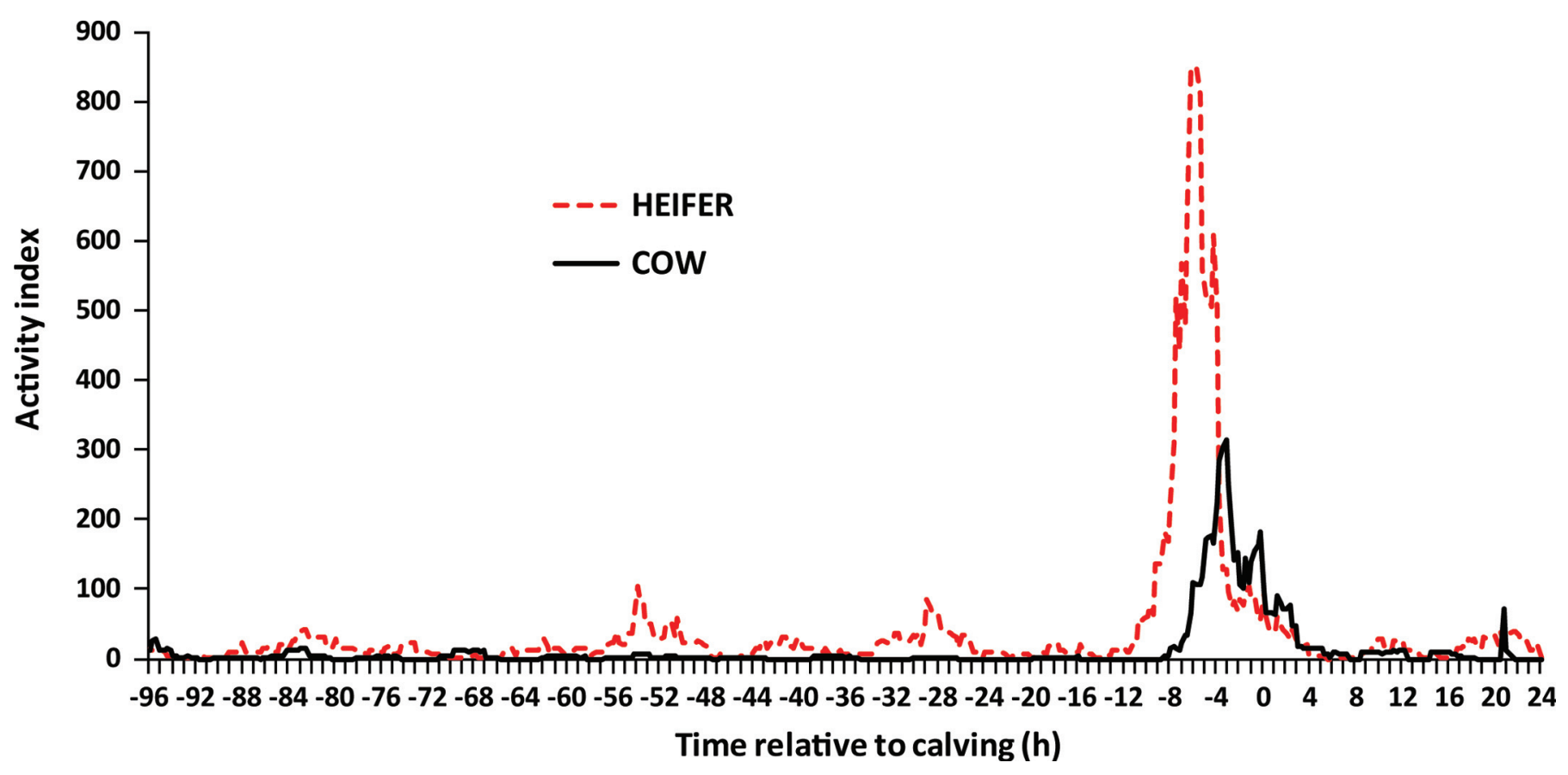

Figure 2. An example schematic representation of the activity index for one heifer and one cow experiencing unassisted births. The activity patterns for both heifers and cows were computed and reported hourly using the activity index $96 \mathrm{~h}$ before and $24 \mathrm{~h}$ after parturition. The lines show the hourly behavioral activity as a pregnant heifer (dashed line) or cow (solid line) approaches parturition, goes through labor and calf birth $(0 \mathrm{~h})$, and initiates lactation. For the heifers, the activity index predicted parturition $9 \mathrm{~h} 15 \mathrm{~min}$ before calf birth $(0 \mathrm{~h})$. For the cow, the activity index predicted parturition $6 \mathrm{~h} 30 \mathrm{~min}$ before calf birth $(0 \mathrm{~h})$. Color version available online. 
Hypocalcemia at calving has been associated with dystocia (Curtis et al., 1983). Although no differences were observed in daily standing bouts between control and those cows with subclinical hypocalcaemia in the $7 \mathrm{~d}$ before calving (Jawor et al., 2012), cows with subclinical hypocalcemia stood longer during the 24-h period before parturition regardless of the difficulty at birth (Jawor et al., 2012). This suggests that these cows may experience increased discomfort at calving. Total serum calcium status at calving was not assessed in the present study; however, none of the prepartum animals (heifers and cows) enrolled in the study had hypocalcemia $7 \mathrm{~d}$ before calving.

In the present study, prepartum heifers and cows had increased number of LB with decreased duration of LB $24 \mathrm{~h}$ before parturition. Increased standing time (Huzzey et al., 2005) or LB (Miedema et al., 2011a,b) has been previously reported in prepartum cows. This pattern of behavioral activity has been described as restless behavior characterized by increased frequency of postural changes (Barrier et al., 2012; Jensen, 2012), commonly observed before calving; thus, it has been attributed to discomfort during the process of calf delivery (Huzzey et al., 2005; Schuenemann et al., 2011). Additionally, the increased number of steps and decreased standing time $24 \mathrm{~h}$ before parturition observed in the present study was also reported $12 \mathrm{~h}$ before calving (Miedema et al., 2011a,b). However, a significant increase in standing time during the active calving period (labor) compared with both pre- and postcalving periods has been reported (Huzzey et al., 2005). Huzzey et al. (2005) moved cows into individual maternity pens approximately $1 \mathrm{~d}$ before calving until $1 \mathrm{~d}$ after calving compared with the present study where cows were moved into individual maternity pens at the onset of calving (AS or appearance of the feet of the calf outside the vulva) and were then immediately moved into postpartum pens after delivery. Perhaps the length of time in the maternity pen (Proudfoot et al., 2013) and facility design might explain, at least in part, the observed differences between studies.

The effect of parity on cow behavioral activity as parturition approaches has been described elsewhere (Wehrend et al., 2006; Miedema et al., 2011a; Schuenemann et al., 2011). In the present study, heifers spent less time standing and had fewer LB $24 \mathrm{~h}$ before calving compared with cows. Variation in behavioral signs such as frequency of transitions from lying to standing (Schuenemann et al., 2011) and restlessness (e.g., pawing, tail raising, and vocalization) have been reported between primiparous and multiparous cows (Wehrend et al., 2006; Miedema et al., 2011a). Pregnant heifers may not have fully acquired a maternal experience and may be prone to restless behavior due to pain before parturition (Wehrend et al., 2006). Because no difference was observed in the predicted time before birth between heifers and cows using the activity index, this variation in physical activity can be modeled using electronic data loggers regardless of parity.

The prediction of parturition in cattle has been investigated using real-time ultrasound (Wright et al., 1988), changes in body temperature (Burfeind et al., 2011), blood 17- $\beta$-estradiol (Shah et al., 2007) or progesterone profile (Matsas et al., 1992), relaxation of pelvic ligament (Dufty, 1971), electrolyte concentration in mammary secretions (Bleul et al., 2006), intravaginal insert devices that are activated when pushed out of the vagina by the AS (Palombi et al., 2013), and video monitoring of cows before calving (Cangar et al., 2008). The technology to monitor physical cow activity for reproduction (Aungier et al., 2012; Kamphuis et al., 2012; Chebel et al., 2013) or rumination (Reith and Hoy, 2012) as well as health events (e.g., locomotion; Chapinal et al., 2011) are management tools available for dairy herds. The changes in calving-related activity, frequent transitions from lying to standing (Schuenemann et al., 2011), and restless behavior (e.g., pawing, walking) during the first stage of labor (Wehrend et al., 2006; Miedema et al., 2011a) are robust parameters that can be combined into an activity index or developed into an algorithm to predict calving time. In the present study, electronic data loggers were used to assess behavioral activity (steps, standing time, and LB) before calf birth. For instance, the activity index developed in this study increased with the ratio between steps and standing time (number of steps per unit of time). Furthermore, both prepartum heifers and cows transition more frequently from standing to lying positions during the first stage of labor; thus, the number of $(\mathrm{LB} / \mathrm{h})^{2}$ was used to increase the weight of this change in behavior on the overall activity index. Using the activity index described above, significant activity change was observed on average $6 \mathrm{~h} 14 \mathrm{~min}$ before calf birth (0 $\mathrm{h})$, with such a shift in behavior noticed in almost $76 \%$ of the prepartum animals at least $4 \mathrm{~h}$ before calving.

For any dairy operation, calving is an essential part of the production system initiating lactation and providing future replacements for the herd. Being able to provide appropriate care at the time of calving in a timely manner is important for survival of both the dam and newborn calf (Lombard et al., 2007). Substantial knowledge exists to prevent calving-related problems (e.g., stillbirth, dystocia); however, this knowledge must be translated into on-farm applications or practices to have a measurable effect at the herd level. For any dairy operation, the identification of imminent signs of calv- 
ing requires skillful personnel and time (monitoring of all prepartum heifers and cows around the clock). The assessment of activity before parturition using electronic data loggers may provide an effective alert system for calving time as opposed to waiting for the imminent signs of labor (appearance of AS or feet of the calf). Therefore, monitoring cow behavior based on real-time, computerized physical activity algorithms may enhance the calving management program (complementary to the typical visual observation by calving personnel) by effectively identifying cows and heifers in need of attention under field conditions.

\section{CONCLUSIONS}

This study provided evidence that dairy cattle approaching parturition showed a distinct behavioral pattern that can predict calf birth on average $6 \mathrm{~h}$ before calving. Electronic data loggers as predictors of parturition in real-time and around-the-clock may facilitate the implementation of a precision calving management program to help reduce the prevalence of calving-related losses such as stillbirth due to late or no interventions. The appropriate time to place the data loggers relative to expected calving date and the activity index will likely need to be refined taking into account the management and logistics of each individual farm relative to when pregnant animals near parturition (grouping and regrouping), and perhaps include other physiological parameters (e.g., rumination) to determine its predictive value for calving (including specificity and sensitivity).

\section{ACKNOWLEDGMENTS}

The authors thank the collaborating dairy farms and their staff for providing the animals used in this study and their assistance during the project. This project was partially supported by the Ohio Dairy Producers Association (Columbus), the Epperson Summer Research Fellow (Columbus, OH), and Coba/Select Sires Inc. (Columbus, OH).

\section{REFERENCES}

Aungier, S. P. M., J. F. Roche, M. Sheehy, and M. A. Crowe. 2012. Effects of management and health on the use of activity monitoring for estrus detection in dairy cows. J. Dairy Sci. 95:2452-2466.

Barrier, A. C., E. Ruelle, M. J. Haskell, and C. M. Dwyer. 2012. Effect of a difficult calving on the vigor of the calf, the onset of maternal behaviour, and some behavioural indicators of pain in the dam. Prev. Vet. Med. 103:248-256.

Bas, S., A. Hoet, P. Rajala-Schultz, D. Sanders, and G. M. Schuenemann. 2011. The use of plastic cover sheaths at the time of artificial insemination improved fertility of lactating dairy cows. J. Dairy Sci. 94:793-799.
Bleul, U., S. Spirig, H. Massig, and W. Kahn. 2006. Electrolytes in bovine prepartum mammary secretions and their usefulness for predicting parturition. J. Dairy Sci. 89:3059-3065.

Burfeind, O., V. S. Suthar, R. Voigtsberger, S. Bonk, and W. Heuwieser. 2011. Validity of prepartum changes in vaginal and rectal temperature to predict calving in dairy cows. J. Dairy Sci. 94:5053-5061.

Cangar, O., T. Leroy, M. Guarino, E. Vranken, R. Fallon, J. Lenehan, J. Mee, and D. Berckmans. 2008. Automatic real-time monitoring of locomotion and posture behaviour of pregnant cows prior to calving using online image analysis. Comput. Electron. Agric. 64:53-60.

Chapinal, N., A. M. de Passille, M. Pastell, L. Hanninen, L. Munksgaard, and J. Rushen. 2011. Measurement of acceleration while walking as an automated method for gait assessment in dairy cattle. J. Dairy Sci. 94:2895-2901.

Chebel, R. C., A. A. Scanavez, P. R. B. Silva, J. G. N. Moraes, L. G. D. Mendonça, and G. Lopes Jr.. 2013. Evaluation of presynchronized resynchronization protocols for lactating dairy cows. J. Dairy Sci. 96:1009-1020.

Curtis, C. R., H. N. Erb, C. J. Sniffen, R. D. Smith, P. A. Powers, M. C. Smith, M. E. White, R. B. Hilman, and E. J. Pearson. 1983. Association of parturient hypocalcaemia with eight periparturient disorders in Holstein cows. J. Am. Vet. Med. Assoc. 183:559-561.

Dufty, J. H. 1971. Determination of the onset of parturition in Hereford cattle. Aust. Vet. J. 47:77-82.

Elischer, M. F., M. E. Arceo, E. L. Karcher, and J. M. Siegfor. 2013. Validating the accuracy of activity and rumination monitor data from dairy cows housed in a pasture-based automatic milking system. J. Dairy Sci. 96:6412-6422.

Ferguson, J. D., D. T. Galligan, and N. Thomsen. 1994. Principal descriptors of body condition score in Holstein cows. J. Dairy Sci. $77: 2695-2703$.

Hunter, A., M. G. Maquivar, S. Bas, J. D. Workman, and G. M. Schuenemann. 2013. Assessment of work shift transition of calving personnel on stillbirth in Holstein dairy cows. J. Dairy Sci. 96:383. (Abstr.)

Huzzey, J. M., M. A. G. von Keyserlingk, and D. M. Weary. 2005. Changes in feeding, drinking, and standing behavior of dairy cows during the transition period. J. Dairy Sci. 88:2454-2461.

Jawor, P. E., J. M. Huzzey, S. J. LeBlanc, and M. A. G. von Keyserlingk. 2012. Associations of subclinical hypocalcemia at calving with milk yield, and feeding, drinking, and standing behaviors around parturition in Holstein cows. J. Dairy Sci. 95:1240-1248.

Jensen, M. B. 2012. Behaviour around the time of calving in dairy cows. Appl. Anim. Behav. Sci. 139:195-202.

Kamphuis, C., B. DelaRue, C. R. Burke, and J. Jago. 2012. Field evaluation of 2 collar-mounted activity meters for detecting cows in estrus on a large pasture-grazed dairy farm. J. Dairy Sci. 95:3045-3056

Lombard, J. E., F. B. Garry, S. M. Tomlinson, and L. P. Garber. 2007. Impacts of dystocia on health and survival of dairy calves. J. Dairy Sci. 90:1751-1760.

Matsas, D. J., R. L. Nebel, and K. D. Pelzer. 1992. Evaluation of an on-farm blood progesterone test for predicting the day of parturition in cattle. Theriogenology 37:859-868.

Miedema, H., M. Cockram, C. Dwyer, and A. Macrae. 2011a. Behavioural predictors of the start of normal and dystocic calving in dairy cows and heifers. Appl. Anim. Behav. Sci. 132:14-19.

Miedema, H., M. Cockram, C. Dwyer, and A. Macrae. 2011b. Changes in the behaviour of dairy cows during the $24 \mathrm{~h}$ before normal calving compared with behaviour during late pregnancy. Appl. Anim. Behav. Sci. 131:8-14.

Noakes, D. E., T. J. Parkinson, and G. C. W. England. 2001. Dystocia and Other Disorders Associated with Parturition. Arthur's Veterinary Reproduction and Obstetrics. 8th ed. Saunders, Philadelphia, PA.

NRC. 2001. Nutrient Requirements of Dairy Cattle. 7th rev. ed. National Academy Press, Washington, DC.

Palombi, C., M. Paolucci, G. Stradaioli, M. Corubolo, P. B. Pascolo, and M. Monaci. 2013. Evaluation of remote monitoring of parturi- 
tion in dairy cattle as a new tool for calving management. BMC Vet. Res. 9:191.

Proudfoot, K. L., J. M. Huzzey, and M. A. G. von Keyserlingk. 2009. The effect of dystocia on the dry matter intake and behavior of Holstein cows. J. Dairy Sci. 92:4937-4944.

Proudfoot, K. L., M. B. Jensen, D. M. Weary, and M. A. G. von Keyserlingk. 2013. Effect of moving dairy cows at different stages of labor on behavior during parturition. J. Dairy Sci. 96:1638-1646.

Reinhardt, T. A., J. D. Lippolis, B. J. McCluskey, J. P. Goff, and R. L. Horst. 2011. Prevalence of subclinical hypocalcemia in dairy herds. Vet. J. 188:122-124.

Reith, S., and S. Hoy. 2012. Relationship between daily rumination time and estrus of dairy cows. J. Dairy Sci. 95:6416-6420.

Schuenemann, G. M., S. Bas, E. Gordon, and J. D. Workman. 2013 Dairy calving management: Description and assessment of a training program for dairy personnel. J. Dairy Sci. 96:2671-2680.

Schuenemann, G. M., I. Nieto, S. Bas, K. N. Galvão, and J. D. Workman. 2011. Assessment of calving progress and reference times for obstetric intervention during dystocia in Holstein dairy cows. J Dairy Sci. 94:5494-5501.

Shah, K. D., T. Nakao, and H. Kubota. 2007. Peripartum changes in plasma estrone sulphate and estradiol-17beta profiles associated with and without the retention of foetal membranes in HolsteinFriesian cattle. J. Reprod. Dev. 53:279-288.

USDA. 2010. Dairy 2007, Heifer Calf Health and Management Practices on U.S. Dairy Operations, 2007. USDA:APHIS:VS, CEAH, Fort Collins, CO.

Wehrend, A., E. Hofmann, K. Failing, and H. Bostedt. 2006. Behaviour during the first stage of labour in cattle: influence of parity and dystocia. Appl. Anim. Behav. Sci. 100:164-170.

Wright, I. A., I. R. White, A. J. F. Russel, T. K. Whyte, and A. J. McBean. 1988. Prediction of calving date in beef cows by real-time ultrasonic scanning. Vet. Rec. 123:228-229. 